\title{
EFEKTIFITAS STERILISASI MENGGUNAKAN ULTRAVIOLET (UV) PADA RUANG PERAWATAN DI RUMAH SAKIT UMUM DAERAH BANYUMAS TAHUN 2016
}

\author{
Restutusi Ayu Waluyo" ${ }^{1)}$, Tri Cahyono ${ }^{2)}$ \\ Jurusan Kesehatan Lingkungan, Politeknik Kesehatan Kemenkes Semarang, \\ Jl. Raya Baturraden KM 12 Purwokerto, Indonesia
}

\begin{abstract}
Abstrak
Latar belakang RSUD Banyumas merupakan rumah sakit tipe B. Ruang perawatan pada RSUD Banyumas adalah ruang perawatan yang melayani penyakit infeksius dan noninfeksius, sehingga berpotensi terjadinya infeksi nosokomial. Tujuan penelitian ini adalah untuk mengetahui efektifitas sterilisasi menggunakan UV pada ruang perawatan di RSUD Banyumas.Jenis penelitian ini adalah penelitian observasional analitik dengan pendekatan cross sectional. Jenis variabel yang digunakan yaitu variabel bebas (penggunaan UV), variabel terikat (angka kuman udara), dan variabel pengganggu (suhu, kelembaban, pencahayaan, luas ventilasi dan volume ruangan). Berdasarkan hasil pemeriksaan Rata - rata angka kuman sebelum sterilisasi adalah 18.500CFU/m3. Rata - rata angka kuman sesudah sterilisasi adalah $8.250 \mathrm{CFU} / \mathrm{m} 3$. Rata-rata suhu pada ruang perawatan adalah $29,50 C$. Rata-rata kelembaban pada ruang perawatan adalah $84,0 \%$. Rata - rata intensitas cahaya pada ruang perawatan adalah 113 lux. Rata - rata luas ventilasi adalah 1,08m2 . Rata-rata volume ruangan pada ruang perawatan adalah adalah 55,8m3.Rata - rata efektifitas sterilisasi adalah (- 56,24\%).Peneliti menyimpulkan penggunaan sterilisasi efektif dalam menurunkan angka kuman udara. Peneliti menyarankan untuk melakukan sterilisasi pada ruang perawatan setiap kali ruangan digunakan.
\end{abstract}

Kata Kunci ： Rumah sakit, angka kuman udara, sterilisasi UV

\begin{abstract}
[The Evectiveness of Using Ultraviolet (Uv) in The Wards Of Rumah Sakit Umum Daerah Banyumas] RSUD Banyumas is a type-B hospital which has wards for infectious treatment and for non-infectious treatment. Therefore, there is potential of nosocomial infection. The objective of the study is knowing the effectiveness of sterilisation using UV in wardS of RSUD Banyumas. The type of the research is an observasion analytical research by using cross sectional approach. The type of variables are the free variable (The use of UV), the dependent variable (The number of germs on the air), and the potential confusing variable (temperature, humidity, lighting, ventilation size, and volume of room).Based on the research, the average of germs before sterilisation is $18.500 \mathrm{CFU} / \mathrm{m} 3$, the average of temperature is $29.5 \mathrm{oC}$, the average of humidity is $84.0 \%$, the average of light intensity is 113 lux, the average of ventilation size is 1.08m2, the average of room volume is $55.8 \mathrm{~m} 3$, and the average of sterilisation effectiveness is (- 56,24\%).The researcher concludes that the use of sterilisation is effective to decrease number of germs on the air. Researcher suggests that sterilization should be done everytime the ward used.
\end{abstract}

Keywords $\quad$ : Hospital, germs air , sterilitation UV

\section{PENDAHUluan}

Rumah sakit sebagai sarana kesehatan, tempat berkumpulnya orang sakit maupun orang sehat, atau dapat menjadi tempat penularan penyakit serta memungkinkan terjadinya pencemaran lingkungan dan gangguan kesehatan, bahwa untuk menghindari risiko dan gangguan kesehatan maka perlu penyelenggaraan kesehatan lingkungan rumah sakit sesuai dengan persyaratan kesehatan (KepMenKes RI No. 1204/MENKES/SK/X/2004).

Menurut hasil penelitian Latifathul Khusna (2014), rata-rata angka kuman udara di ruang radiologi dan ruang ICU di RSUD Banyumas pada

1) Email : restutusiaw@gmail.com

2) Email : tricahyono37@yahoo.co.id ruang radiologi sebesar 270,7 $\mathrm{CFU} / \mathrm{m} 3$ dan ruang ICU sebesar 186,7 CFU/m3 masih dibawah persyaratan Kesehatan Lingkungan Rumah Sakit (200 CFU/m3). Rata-rata kelembaban ruang Radiologi (47\%), ruang ICU (47,5\%). Rata-rata pencahayaan ruang Radiologi 68,22 lux dan ruang ICU 56,24 lux. Hasil Uji U Mann Whitney (U) diketahui ada perbedaan yang bermakna antara jumlah angka kuman udara ruang radiologi dan ruang ICU karena nilai signifikan (2 tailed) lebih kecil dari $\alpha(0,05)$, yaitu 0,047 , maka Ho ditolak. Berdasarkan hasil penelitian tersebut diketahui bahwa tidak ada hubungan antara jumlah angka 
12kuman dengan kualitas fisik di Rumah Sakit Umum Daerah (RSUD) Banyumas. Penggunaan alat untuk melakukan sterilisasi pada ruangan yang telah dilakukan di RSUD Banyumas adalah menggunakan Ozon, ULV, dan Sinar UV, namun pihak rumah sakit belum mengetahui keefektifan dan belum dilakukannya penelitian pada ketiga alat tersebut.

Atas dasar ini peneliti bermaksud melakukan pengukuran terhadap jumlah angka kuman udara pada ruang perawatan Teratai dan Bougenvil RSUD Banyumas. Pertimbangan hal tersebut diatas peneliti tertarik menjadikan penelitian dengan judul "Efektifitas Sterilisasi Menggunakan UV pada Ruang Perawatan di Rumah Sakit Umum Daerah Banyumas Tahun 2016”.

\section{BAHAN DAN METODE}

Variabel bebas dalam penelitian ini adalah penggunaan UV. Variabel terikat dalam peneltian ini adalah angka kuman di udara. Variabel pengganggu dalam penelitian ini adalah suhu, pencahayaan, kelembaban, luas ventilasi, volume ruangan.Populasi dalam penelitian ini adalah semua ruang perawatan di RSUD Banyumas. Sampel yang digunakan dalam penelitian ini adalah teknik incidental sampling. Titik pengambilan dilakukan di tengah ruangan.

\section{HASIL DAN PEMBAHASAN}

Pengukuran dan pemeriksaan kualitas fisik dilakukan pada tanggal 16, 23 dan 30 April 2016, alat yang di gunakan untuk pengambilan sampel yaitu impinger, tempat pengambilan sampel yaitu di Ruang perawatan (Cempaka, VK, dan $\mathrm{PH}$ ) dengan 1 titik pengambilan sampel sebelum dilakukan perlakuan, dan 1 titik pengambilan sampel setelah dilakukan perlakuan.

\section{Angka Kuman Udara Sebelum Sterilisasi}

Hasil dari pengambilan sampel angka kuman udara sebelum sterilisasi sebagai berikut :

Hasil angka kuman udara di ruang perawatan RSUD Banyumas sebelum dilakukan sterilisasi adalah $7.750 \mathrm{CFU} / \mathrm{m}^{3}$, $30.000 \mathrm{CFU} / \mathrm{m}^{3}$ dan 17.750 $\mathrm{CFU} / \mathrm{m}^{3}$. Rata - rata angka kuman sebelum sterilisasi adalah $18.500 \mathrm{CFU} / \mathrm{m}^{3}$. Angka kuman udara tertinggi sebelum sterilisasi adalah 30.000 $\mathrm{CFU} / \mathrm{m}^{3}$, angka kuman udara terendah sebelum sterilisasi adalah $7.750 \mathrm{CFU} / \mathrm{m}^{3}$

Berdasarkan data diatas Angka kuman udara dipengaruhi oleh kadar debu, suhu dan kelembaban. Suhu yang tinggi akan menyebabkan kelembaban yang tinggi dan dapat menyebabkan perkembangan pada kuman, maka dari itu untuk mengurangi angka kuman di udara maka harus adanya AC (air conditioner) sebagai pengendali suhu dan kelembaban, agar kuman diudara tidak dapat berkembang.

\section{Angka Kuman Udara Sesudah Sterilisasi}

Hasil angka kuman udara di ruang perawatan RSUD Banyumas sesudah dilakukan sterilisasi adalah 1.250 CFU/m $\mathrm{m}^{3}, 7.500 \mathrm{CFU} / \mathrm{m}^{3}$ dan 16.000 $\mathrm{CFU} / \mathrm{m}^{3}$. Rata - rata angka kuman sesudah sterilisasi adalah $8.250 \mathrm{CFU} / \mathrm{m}^{3}$. Angka kuman udara tertinggi setelah sterilisasi adalah 16.000 $\mathrm{CFU} / \mathrm{m}^{3}$, angka kuman udara terendah setelah sterilisasi adalah $1.250 \mathrm{CFU} / \mathrm{m}^{3}$.

Berdasarkan data diatas Angka kuman udara dipengaruhi oleh kadar debu, suhu dan kelembaban. Suhu yang tinggi akan menyebabkan kelembaban yang tinggi dan dapat menyebabkan perkembangan pada kuman, maka dari itu untuk mengurangi angka kuman di udara maka harus adanya AC (air conditioner) sebagai pengendali suhu dan kelembaban, agar kuman diudara tidak dapat berkembang.

Hasil Pengukuran Suhu, Kelembaban, Intensitas Cahaya, Luas Ventilasi, Volume Ruangan dan Kepadatan Hunian

\section{Suhu}

Pengukuran suhu dilakukan ditengah-tengah ruang perawatan menggunakan termohygrometer. Suhu di ruang perawatan RSUD Banyumas pada saat dilakukan pengukuran diperoleh hasil $29,4^{\circ} \mathrm{C}$, $28,6^{\circ} \mathrm{C}$ dan $30,5^{\circ} \mathrm{C}$. Rata-rata suhu pada ruang perawatan adalah $29,5^{\circ} \mathrm{C}$, suhu tertinggi pada ruang perawatan adalah $30,5^{\circ} \mathrm{C}$, suhu terendah adalah 28,6 ${ }^{\circ} \mathrm{C}$.

Suhu ruangan harus memenuhi syarat yang berlaku, suhu udara yang tidak memenuhi standar mendukung keberadaan kehidupan pada bakteri, tidak terdapatnya AC (Air Conditioner) berbahan ion plasma pada ruang perawatan adalah salah satu faktor yang mempengaruhi adanya angka kuman udara pada ruang perawatan. Sehingga perlu ditambahkannya AC berbahan ion plasma pada ruang perawatan agar berkurangnya angka kuman udara dan sebagai pengatur suhu didalam ruang perawatan dengan cara kerja ion plasma sehingga dapat menurunkan angka kuman diudara.

\section{Kelembaban Udara}

Pengukuran kelembaban dilakukan ditengahtengah ruang perawatan menggunakan hygrometer. Kelembaban di ruang perawatan RSUD Banyumas pada saat dilakukan pengukuran diperoleh hasil 88,7\%, 79,8\% dan 83,7\%. Rata-rata kelembaban pada ruang perawatan adalah $84,0 \%$, Kelembaban tertinggi adalah $88,7 \%$, kelembaban terendah adalah $79,8 \%$.

Kelembaban udara ruangan harus memenuhi standar, karena kelembaban adalah salah satu faktor yang mempengaruhi pertumbuhan bakteri di udara. Untuk menjaga kelembaban ruang optimum, maka sebaiknya ruang perawatan diberi AC sebagai pengatur suhu dan juga kelembaban, agar mikroba tidak dapat tumbuh di dalam ruang perawatan. 
Pembersihan AC juga perlu dilakukan minimal satu bulan sekali agar bakteri tidak menempel pada AC.

\section{Intensits Cahaya}

Pengukuran intensitas cahaya dilakukan ditengah-tengah ruang perawatan menggunakan Lux meter. Intesitas cahaya di ruang perawatan RSUD Banyumas pada saat dilakukan pengukuran diperoleh hasil 70 lux, 138 lux dan 133 lux. Rata rata intensitas cahaya pada ruang perawatan adalah 113 lux. Intensitas cahaya tertinggi adalah 138 lux, intensitas cahaya terendah adalah 70 lux

Pencahayaan yang baik dan memenuhi syarat penting bagi ruang perawatan, sebaiknya ruang perawatan yang pencahayaannya masih kurang memenuhi standar diberi armatur pada lampu tersebut, dengan cara meletakan armatur di dalam lampu dan meletakannya di tengah-tengah ruangan, karena cahaya yang kurang merupakan kondisi yang disukai bakteri karena dapat tumbuh baik pada kondisi yang gelap.

\section{Luas Ventilasi}

Pengukuran luas ventilasi dilakukan menggunakan meteran. Luas ventilasi di ruang perawatan RSUD Banyumas pada saat dilakukan pengukuran diperoleh hasil $0,63 \mathrm{~m}^{2}, 0,53 \mathrm{~m}^{2}$ dan $2,09 \mathrm{~m}^{2}$. Rata-rata luas ventilasinya adalah $1,08 \mathrm{~m}^{2}$. Hasil efektifitasnya adalah 10,5\% , 3,15\% dan $13,1 \%$. Rata-rata efektifitas luas ventilasinya adalah $8,91 \%$.

Ventilasi yang belum memenuhi standar berpengaruh terhadap suhu dan kelembaban di dalam ruangan, adanya AC di dalam ruang perawatan dapat memperbaiki suhu dan kelembaban yang ada di dalam ruang perawatan sehingga perkembangan kuman di udara tidak dapat lagi berkembang. Pengaturan AC juga penting untuk udara yang ada di dalam ruang perawatan, dan pembersihan AC juga sangat penting agar udara yang masuk kedalam ruangan tidak kotor dan membawa bakteri.

\section{Volume Ruangan}

Pengukuran volume ruangan dilakukan menggunakan meteran. Volume ruangan di ruang perawatan RSUD Banyumas pada saat dilakukan pengukuran diperoleh hasil $27,0 \mathrm{~m}^{3}, 50,4 \mathrm{~m}^{3}$ dan $90,0 \mathrm{~m}^{3}$. Rata-rata volume ruangan pada ruang perawatan adalah adalah 55,8m3. Volume ruangan tertinggi $90,0 \mathrm{~m}^{3}$, volume ruangan terendah adalah $27,0 \mathrm{~m}^{3}$.

Volume ruangan yang sudah memenuhi standar diusahakan agar tetap memenuhi standar, dengan meminimalkan pengunjung kedalam ruang perawatan agar pasien merasa nyaman dan menghindari banyaknya kuman yang dibawa oleh pengunjung kedalam ruang perawatan.

\section{Hasil Perhitungan Efektifitas Sterilisasi}

Hasil perhitungan efektifitas sterilisasi dalam menurunkan angka kuman di ruang perawatan, nilai efektifitas sterilisasi adalah (-83,87\%), (-75\%) dan ($9,85 \%)$. Rata - rata efektifitas sterilisasi adalah ($56,24 \%)$, efektifitas tertinggi adalah $(-9,85 \%)$, efektifitas terendah adalah $(-83,87)$. Berdasarkan data diatas maka sterilisasi UV efektif dalam menurunkan angka kuman diudara.

Hasil negatif ( - ) pada perhitungan efektifitas sterilisasi menunjukan bahwa terjadinya penurunan angka kuman sebelum dan sesudah sterilisasi. Sterilisasi menggunakan Sinar UV sebaiknya sering digunakan agar angka kuman pada udara dapat turun dan mengurangi terjadinya infeksi nosokomial pada pasien. Untuk mengetahui umur dari alat atau lampu Ultraviolet tersebut sebaiknya terdapat buku atau catatan setiap kali penggunaan alat, tujuannya untuk mengetahui sudah berapa jam penggunaan alat tersebut karena untuk masa aktif alat tersebut hanya 3000 jam.

\section{Hasil Analisis Statistik}

Berdasarkan data hasil pemeriksaan angka kuman udara di ruang perawatan rata - rata angka kuman udara sebelum sterilisasi adalah 7.750 $\mathrm{CFU} / \mathrm{m}^{3}$ - $30.000 \mathrm{CFU} / \mathrm{m}^{3}$. Rata - rata angka kuman setelah sterilisasi adalah $1.250 \mathrm{CFU} / \mathrm{m} 3$ - 16.000 $\mathrm{CFU} / \mathrm{m} 3$. Menurut hasil perhitungan menggunakan SPSS versi 17 dengan paired T-test diketahui nilai signifikan (2 tailed) lebih besar dari $\alpha(0,05)$, yaitu $(0,244)$ maka Ho diterima, sehingga tidak ada perbedaan antara jumlah angka kuman udara sebelum dan sesudah disterilisasi di ruang perawatan RSUD Banyumas.

Sebaiknya sebelum dilakukan sterilisasi dilakukan pembersihan ruangan terlebih dahulu secara benar agar angka kuman udara didalam ruangan tidak melebihi standar ketentuan KepMenKes. Kemudian perlu ditambahkannya kipas angin pada saat dilakukannya sterilisasi UV agar adanya sirkulasi udara didalam ruang perawatan dan mengangkat /mengeluarkan bakteri yang ada di bawah tempat tidur, sela-sela lemari dan perabotan lainnya sehingga bakteri tersebut dapat terkena sinar ultraviolet. Kemudian perlu diketahui apakah dosis Ultraviolet saat dilakukannya kegiatan sterilisasi masih ada atau tidak agar mengetahui bahwa alat tersebut bekerja secara maksimal atau tidak.

\section{SIMPULAN DAN SARAN}

\section{Simpulan}

Rata - rata angka kuman sebelum sterilisasi adalah $18.500 \mathrm{CFU} / \mathrm{m}^{3}$. Angka kuman udara tertinggi sebelum sterilisasi adalah $30.000 \mathrm{CFU} / \mathrm{m}^{3}$, angka kuman udara terendah sebelum sterilisasi adalah 7.750 CFU/m $\mathrm{m}^{3}$

Rata - rata angka kuman sesudah sterilisasi adalah $8.250 \mathrm{CFU} / \mathrm{m}^{3}$. Angka kuman udara tertinggi setelah sterilisasi adalah $16.000 \mathrm{CFU} / \mathrm{m}^{3}$, angka 
kuman udara terendah setelah sterilisasi adalah 1.250 $\mathrm{CFU} / \mathrm{m}^{3}$.

Hasil pengukuran suhu, kelembaban, intensitas cahaya, luas ventilasi, volume ruangan dan kepadatan hunian pada ruang perawatan di RSUD Banyumas adalah :

Rata-rata suhu pada ruang perawatan adalah $29,5^{\circ} \mathrm{C}$, suhu tertinggi pada ruang perawatan adalah $30,5^{\circ} \mathrm{C}$, suhu terendah adalah $28,6^{\circ} \mathrm{C}$

Rata-rata kelembaban pada ruang perawatan adalah 84,0\%, Kelembaban tertinggi adalah 88,7\%, kelembaban terendah adalah 79,8\%.

Rata - rata intensitas cahaya pada ruang perawatan adalah 113 lux. Intensitas cahaya tertinggi adalah 138 lux, intensitas cahaya terendah adalah 70 lux .

Rata-rata luas ventilasi pada ruang perawatan adalah $1,08 \mathrm{~m}^{2}$, luas ventilasi tertinggi adalah $2,09 \mathrm{~m}^{2}$, dan luas ventilasi terendah adalah $0,53 \mathrm{~m}^{2}$.

Rata-rata volume ruangan pada ruang perawatan adalah adalah $55,8 \mathrm{~m}^{3}$. Volume ruangan tertinggi $90,0 \mathrm{~m}^{3}$, volume ruangan terendah adalah $27,0 \mathrm{~m}^{3}$

Kepadatan hunian di ruang perawatan RSUD Banyumas tidak terdapat pasien/ penghuni didalam ruang perawatan, namun ada beberapa peralatan yang berada didalam ruangan seperti tempat tidur (bad), lemari (troli makan) dan tiang infus,

Rata-rata efektifitas sterilisasi dalam menurunkan angka kuman udara di ruang perawatan RSUD Banyumas adalah - 56,24 \%.

Hasil analisis statistik diketahui nilai signifikan (2 tailed) lebih besar dari $\alpha(0,05)$, yaitu $(0,244)$, maka Ho diterima sehingga tidak ada perbedaan antara jumlah angka kuman udara sebelum dan sesudah disterilisasi di ruang perawatan RSUD Banyumas.

\section{Saran}

1. Bagi Rumah Sakit

Diharapkan kepada pihak rumah sakit untuk lebih menjaga kualitas udara ruangan dengan melakukan sterilisasi minimal dua kali dalam seminggu.

Sebaiknya pihak rumah sakit menambahkan AC (air conditioner) dalam ruangan untuk mengatur suhu dan kelembaban ruangan agar tetap stabil dan AC yang digunakan sebaiknya jenis AC yang terdapat ion plasma yang berfungsi untuk membunuh kuman yang ada di dalam ruangan.

2. Bagi Peneliti Lain

Sebaiknya peneliti lain lebih memperluas wawasan dengan menambah jumlah variabel yang akan diteliti seperti perilaku pasien, penunggu pasien, dan cuaca pada saat pengambilan sampel, untuk mengetahui perbedaan dengan peneliti sebelumnya. Kemudian sebaiknya peneliti lain menguji kipas angin saat pelaksanaan strerilisasi UV untuk melihat efektifitasnya.

\section{DAFTAR PUSTAKA}

\section{Aziz Alimul Hidayat, 2007. Pengertian}

Dyah Moriska Candra, 2012 , Studi komparasi angka kuman udara ruang perawatan kenanga kelas 2 dan 3 di rsud prof. dr. margono soekarjo tahun 2012: Purwokerto Departemen Kesehatan RI Politeknik Kesehatan Semarang Jurusan Kesehatan Lingkungan Purwokerto,

Indan Entjang, 2003, Mikrobiologi Dan Parasitologi, Bandung: PT. Citra Aditya Bakti

Inas sholihah, 2015. Pengaruh faktor lingkungan fisik terhadap pertumbuhan mikroorganisme. Surakarta : Blogspot

Jurnal Administrasi Bisnis, 2015, Analisis Efektivitas Penerimaan dan Pertumbuhan Pajak Restoran sebagai Salah Satu Sumber Pendapatan Asli Daerah (PAD), at administrasibisnis.blogspot.studentjournal.u b.ac.id (diunduh tanggal 18 Februari 2016)

Lathifatul khusna 2014 .Studi angka kuman udara di ruang radiologi dan ruang ICU RSUD Banyumas tahun 2014, Purwokerto : Departemen Kesehatan RI Politeknik Kesehatan Semarang Jurusan Kesehatan Lingkungan Purwokerto

Lud Waluyo, 2007, Mikrobilogi Umum Cetakan Ketiga, Malang : UMM Press Universitas Terbuka

Pelczar, M.J dan E.C.S Chan, 2008, Dasar-dasar Mikrobiologi II, terjemahan oleh Ratna Siri hadioetomo dkk, Jakarta: Universitas Indonesia

Siti Laela Qomariyah, 2011, Studi komparasi angka kuman udara sebelum dan sesudah desinfeksi dengan bahan didecyldiethylammonium chloride di kamar isolsi ruang dahlia rsud prof. dr. margono soekarjo tahun 2011, Purwokerto: Departemen Kesehatan RI Politeknik Kesehatan Semarang Jurusan Kesehatan Lingkungan Purwokerto

Sri wildani A, 2014. http://pustaka.poltekkes-pdg .ac.id// index.php?p =show_detail\&id=2105 diakses pada tanggal 27 juni 2016 pukul 18:08 
Suparmin, 2008, Hubungan Kualitas Lingkungan Fisik Dengan Angka Kuman Udara Ruang Perawatan Di Rumah Sakit Prof. Dr. Margono Soekarjo Purwokerto, Makalah
Pada Kuliah Perdana Semester Genap TA. 2008/2009, Purwokerto: Jurusan Kesehatan Lingkungan Purwokerto 